\title{
Exploration and Practice of the Large-scale Equipment Sharing Platform
}

\author{
Jiarong Pan ${ }^{1}$, Zhongxu Dai ${ }^{1, a, *}$, Chunli $\mathrm{Lu}^{2, \mathrm{~b}, \star}$, Xinhua Zhou², Jing Chen ${ }^{2}$ \\ ${ }^{1}$ College of Chemistry and Life Sciences, China Three Gorges University, Yichang, 443002, China \\ ${ }^{2}$ Department of Laboratories \& Assets Administration, China Three Gorges University, Yichang, \\ 443002, China
}

aemail: daizx@ctgu.edu.cn, bemail: 13972603508@139.com (corresponding author)

Keywords: Large-scale equipment; Sharing platform; Exploration and practice; Utilization efficiency

\begin{abstract}
In order to improve the utilization efficiency of large-scale equipment, it has been explored and practiced to build a university-level large-scale equipment sharing platform including scientific management, innovative models with special characteristics, active exploration, an incentive system and scientific evaluation system under analyzing the problem of large-scale equipment utilization. All of these promote construction of the sharing platform and take full advantage of the Large-scale equipments. The platform utilized large-scale equipment more efficiently and played a more and more important role in the field of teaching, scientific research and social services.
\end{abstract}

\section{Introduction}

Large-scale equipments (LEs) are not only important essential conditions of personnel training, scientific research and social services, but also a symbol of university standards and comprehensive strength. The efficient utilization of large instruments in the laboratory is crucial for the teaching and scientific research. Since all disciplines of college of Chemistry and Life Sciences are highly experimental, LEs are required to provide support for teaching and scientific research.

In the past, it was a common phenomenon of equipment being "locked up" due to three reasons. First of all, there is no sharing system. The equipment is placed in relative laboratories without a convenient management system. Access to the equipments is not available for faculty and students from other labs though the equipment is bought by school funding. Secondly, school funding sometimes is only responsible for the purchase of the equipment. The maintenance of equipment in specific labs depends on the funding that relative professors can secure, which naturally adds to the cost of "borrowing" the equipment. Thirdly, the job of administrators of the lab equipment is not just to close off windows or wipe dust. More importantly, they are the supervisors on the operations of the equipment, and sometimes are irreplaceable operators. The job is demanding both scientific expertise and operational capacity. Therefore, how to make the LE more convenient by a sharing platform is a key problem for most users.

Recent years, the college laboratory has been rapidly developed. Because the equipment investment increased greatly, the college has had 34 equipments at cost of 16 million RMB Yuan and equipment per student is worth nearly 30 thousands. LE has played a positive role to improve the quality of teaching and scientific research level of the College. It is of great significance to use the equipment shared platform to maximize the utilization of the equipment and to maintain the integrity of the equipment.

University-level lab equipment sharing platform covering chemistry, agriculture, life sciences, environment sciences, medicine and electron microscopy has been established since 2008. Owing to some useful exploration in the experimental equipment management system, management model and equipment maintenance, LE sharing platform have achieved remarkable results in teaching, scientific research and social services. In the past two years, 16 research projects were in progress by the use of large equipments. Besides, more than 280 papers and 8 patents were published, 80 million economic benefits has been generated. Two achievements have been awarded the second 
prize of scientific and technological achievements in Hubei province. The laboratory has organized a number of training courses of analysis and testing technology for the enterprises in Yichang district. 75 quality inspectors completed the training course. Moreover, 227 teachers and students were trained to obtain a LE operation certificate.

\section{Scientific Management of the Equipments Sharing Platform}

LEs were acquired by different purchase funds belong to different departments of the college, so scientific management of the sharing platform is needed to mobilize the enthusiasm of all sectors and to promote the internal departmental interaction.

One task of LE management includes the management system research and realization of open and sharing. Another main task is to change the concept of "Someone who bought it can use it, pursuit of small but complete" to "Do not care for owning it, but seek to use it". Concept change can promote the establishment of institutional mechanisms vigorously and achieve the enhancement of large-scale instrument and equipment utilization and investment returns ultimately. So, more and more large-scale instruments and equipments can be put into teaching, research and academic building effectively. So that equipment management can play a greater role in universities construction.

Breaking the small and complete management concept, the college formed united LE resource sharing pattern under the leadership of the college. The sharing platform improved the coordination between departments, center and projects. Furthermore, participated by the society, the sharing platform combined industry, teaching and research together. Departments and personnel linkage mechanism and policy was established to encourage the leaders from different departments and research projects to participate in the building of LEs sharing platform. Scientifically matched to each instrument, Ph. D. and professors as the main unit administrator are responsible for the day-to-day management, maintenance and operation of the instruments.

Right rules of the large equipments sharing platform were improved to guarantee the large equipment were efficiently shared. Since the large equipment sharing platform was built in China Three Gorges University, management regulations of LEs were constituted and constantly revised in practice to make it clear that the construction, management, shared services and evaluation of rewards of large equipments. For the reason, LEs play a more and more role in the schools large scientific instruments resource sharing platform.

The college teachers generally agreed that the large instruments are more convenient to use and provide good service. The LEs obtained obvious benefits through the scientific management of the equipments sharing platform. Nuclear magnetic resonance spectrometer, ICP-MS and LC-MS have been in place after finalizing the new equipments installation and commissioning. Since its establishment, the platform has been providing better and better service. Almost all newly purchased equipment is running at full capacity. Perfect management mechanism of the sharing platform make these instruments put into use quickly and generate significant yields as soon as possible in the field of teaching, scientific research and social services.

\section{Innovative Models with Special Characteristics}

The equipment management focuses on the improvement of use efficiency. The scientific, standard, efficient and special characteristics management of large instruments is an effective way to realize the high efficiency. The reasonable usage pattern of LE management has been explored, the allocation of resources have been optimized. The unique characteristics of the large instrument platform management mode have been formed, they have been meeting the needs of teaching and research and social services in college of chemistry and life sciences.

First, most courses and scientific research in the college of chemistry and life sciences are characteristic of continuity and time-limited. For example, the synthesis procedure of a chemical compounds can not stop until the end of reactivity. In order to prevent product deterioration, the chemical compounds should be analyzed as soon as the synthesis was completed. This requires the 
LE should be time-opening, space-opening and technology-opening. We accept appointments at all time and keep appointments regardless of during working hours or at rest time.

Before the establishment of the sharing platform, the users usually had to wait for a long time before accessing the lab equipment of other labs because they had nowhere to know about the time arrangement of experiments in other labs. Now the sharing platform offers almost complete sets of $\mathrm{LE}$ and online appointment, ensuring the flexibility of arrangement of experiments.

The LEs are operated in flexible manner for different people. For example, graduate student who need exclusively to use the equipment to finish dissertation was arranged to operate the instrument alone a period of time. We arrange simulation experiments and group experiment in undergraduate experiment courses. In order to increase the operation time of every student, the number of experimental groups was increased to decrease the size of each group. For some widely and high-frequency used laboratory instruments, a united operation schedule is optimized according to all customers' appointments. The useful life of the equipment depends mainly on the maintainability. Equipment maintenance process and system were established to ensure maximization of equipment up-time.

One full-time person was designated to manage the professional equipment with single specific application. For unskilled people, improper use can easily lead to damage to the professional instrument such as UV spectrophotometer. So the instrument manuals, technical application materials, the main specifications and scopes of work for the special equipment following the instructions were compiled together. All the information were sorted out and put into a computer system to facilitate teachers and students to use the instruments. This method not only ensures the safety of instrument operation, but also improves the utilization efficiency of the professional equipments.

Large-scale precision instruments are managed by a professional, effective team with abundant experience. The group are always led by $\mathrm{Ph}$. Ds in related field and advanced laboratory technicians with strong scientific research ability, management ability and strong devotion to duty. To ensure safe and effective operation of the LEs in life cycle, the project team is not only responsible for the operation, daily maintenance of the instrument, but also manage the teaching courses, scientific research, function development further, external and internal service. The large instruments operation is managed through the job card system. All teachers who need to use LE must be trained and passing the examination to get the job card before they used the instrument. Until the above procedures finished, the equipments manager can allow competent teacher to operate the equipments independently.

It is an effective way to manage the LEs through the exploration and practice of the above management mode. According to the different types of instruments and different experimental requirements, adopting different management models is conducive to maximize the benefit with limited funds and existing equipment. A person can be proficient in operating a certain type of instrument, but it is difficult for him to be familiar with all instruments. Therefore, different management models are helpful to improve the manager' ability of LEs operation and maintain. The model setting for the experiment courses can use the existing valuable equipment for research and systematic experimental teaching. It can develop students' experimental operational skills and help to improve the research ability of students to use LE. External cooperation can not only help some units to carry out important research tasks, but also promote technology capability with technical exchange. At the same time, the funds introduced from social projects can improve teaching and research conditions to form a virtuous circle.

\section{Active Exploration and Scientific Evaluation}

The open fund has been established in university for LEs sharing effectively mobilize the enthusiasm of equipment managers, social and college customers to produce beneficial results with LEs. In the past two years, LEs sharing fund had committed around 160 thousand CNY for the equipment sharing projects in college of chemistry and life sciences. The economic benefit of these projects has been reaching 330 thousand CNY. 
The funds can not only solve the lack of research funding for the customer, but also ensure the progress of related work on the instruments. At the same time, the equipment manager supported by the funds can effectively maintenance and operate the equipments. The university encourages teachers with research project to apply for open sharing fund of LE and assures the transfer of project funds in time. Finally, mechanism innovation plays an important role for large equipment in teaching, research and social services. It not only ensured the normal operation of large equipment, but also fully mobilized the enthusiasm of managers and customers.

Scientific evaluation of large instruments is helpful to form a perfect service system and a good working mechanism. It is deeply realized from our longtime LE management, first-class equipment, first-class scientific management, first-class technology, first-class service quality and first-class scientific evaluation are essential key factors to achieve improved efficiency and good benefits of the LEs. In the daily management of the equipment, large equipment managers should firstly be familiar with the performance and operation of the equipment. Secondly, they should strictly enforce the rules for equipment maintenance and calibration to ensure the equipment is in good working condition and the experimental data is accurate and reliable. Thirdly, they should develop the further functions of equipments to maximize the equipments utilization. Fourthly, they should make the schedule of the equipment for all appointments to ensure the smooth development of teaching, research and other work. Finally, they should continuously promote the efficiency of equipment in practice and share the experience.

The college of chemistry and life sciences made efforts on the meaningful exploration of LE utilization on the shared platform. According to device characteristics and customers' needs, the local advantage sharing platform with innovative management modes is continuously optimized in practice to meet the teaching research and social service needs. The sharing platform characterized by integrated management, optimization of the resources allocation, highlighting share, coordination, innovative mechanisms and scientific evaluation played a more and more important role in scientific research, personnel training, social services and technological innovation. The cross-institutions and cross-regional sharing platform has been running more widely so far. Therefore, the further innovative exploration of sharing platforms in practice is necessary to expand the application areas and provide excellent service to achieving advanced benefits.

\section{References}

[1] Jichuan Zhang, Junjie Chen, Service-oriented Large-scale Science Instruments Shareable Platform[J]. Journal of Taiyuan University of Technology, 2009(40)130-133.

[2] Jinchi Zhou, Lanzhen Wang, Some Problems in Construction of Sharing System for LEs in Universities[J]. Research and Exploration in Laboratory, 2012(3l)183-186.

[3] Huadong Wang, Lei Cao, Research and Design of the Large Precision Instrument Sharing Platform Based on the SOA Integration Framework[J]. Laboratory Science. 2012(15)199-202.

[4] Bin Chen, Architecture Design and Sharing Platform of Large-scale Scientific Instrument[J]. Journal of Chongqing Institute of Technology(Natural Science Edition). 2009(11)110-112.

[5] Wenhui Yue, Nai'er Yu and so on. The Construction of Instrument Sharing Platform Based on GIS[J]. Research and Exploration in Laboratory. 2010(29)178-181.

[6] Yuqin Zhang, Realization Resources Sharing Measure and Suggestion[J]. Science \& Technology Information. 2009(5)118, 116.

[7] Hongda Wang, Min Liu, Shijun Chen, Study on Efficiency of Equipment Shared by Universities[J]. Journal of Tianjin Polytechnic University. 2007(26)71-74.

[8] Tianwei Huang, Decheng Bai, Wending Zhang, Measures and Shared-mechanism for the Opening-up Large Instruments and Equipments[J]. Research and Exploration in Laboratory. 2008(27)155-158. 